\title{
PROPOSTA DE IMPLANTAÇÃO DO BALANCED SCORECARD COMO FERRAMENTA ESTRATÉGICA DE APOIO A DECISÃO EM UM BATALHÃO DA POLÍCIA MILITAR DO ESTADO DA PARAÍBA
}

\section{PROPOSAL FOR THE IMPLEMENTATION OF THE BALANCED SCORECARD AS A STRATEGIC TOOL FOR DECISION SUPPORT IN A BATTLE OF PARAÍBA STATE MILITARY POLICE}

\author{
Nathália Gabriel Gomes \\ Centro Universitário de João Pessoa - UNIPÊ \\ E-mail: nathaliapsique1@,gmail.com \\ Alan Santos de Oliveira \\ Universidade Federal do Ceará (UFC) \\ E-mail: asoalansantos@gmail.com \\ Francisco Formiga de Souza \\ Centro Universitário de João Pessoa - UNIPÊ \\ E-mail: francisco.formiga@unipe.edu.br
}

\section{RESUMO}

Objetivou-se nesse estudo apresentar uma proposta de implantação do Balanced Scorecard (BSC) no $1^{\circ}$ batalhão da Polícia Militar da Paraíba (PMPB). Como objetivos específicos: a) analisar a realidade estratégica da instituição; b) identificar quais os pontos de melhorias do batalhão na visão dos policiais militares que fazem parte de seu efetivo; c) analisar o plano estratégico atual do batalhão, enfocando a formulação dos objetivos nas quatro perspectivas estabelecidas no BSC e relações de causa e efeito. Utilizou-se uma abordagem qualitativa por ter sido realizada uma entrevista semiestruturada com o analista criminal da Secretaria de Estado da Segurança e da Defesa Social da Paraíba (SESDS), para entender a realidade estratégica da instituição e quantitativa por ter sido aplicado questionários com amostragem de 146 policiais que respondem ao $1^{\circ}$ batalhão na intenção de identificar o ponto de vista dos policiais militares frente à instituição. Assim, foi possível propor o BSC e suas relações de causa e efeito, traçando estratégias e métricas para todas as perspectivas, mas com ênfase na perspectiva sociedade, pois se trata da principal razão de criação de valor. Espera-se que os resultados apresentados contribuam tanto para o meio acadêmico como para a PMPB, uma vez que a aplicabilidade do BSC pode influenciar na melhoria de gestão.

Palavras-chave: Balanced Scorecard; Polícia Militar; Planejamento Estratégico.

\section{ABSTRACT}

The objective of this study was to present a proposal to implement the Balanced Scorecard (BSC) in the 1st Battalion of the Paraiba Military Police (PMPB). As specific objectives: a) to analyze the strategic reality of the institution; b) identify the points of improvement of the battalion in the view of the military police that are part of its force; c) Analyze the battalion's current strategic plan, focusing on the formulation of objectives in the four perspectives 
established in the BSC and cause and effect relationships. A qualitative approach was used because a semi-structured interview was conducted with the criminal analyst of the State Secretariat of Security and Social Defense of Paraiba (SESDS), to understand the institution's strategic reality and quantitative because it was applied questionnaires with sample sampling. 146 police officers who respond to the 1st battalion in order to identify the point of view of military police towards the institution. Thus, it was possible to propose the BSC and its cause and effect relationships, outlining strategies and metrics for all perspectives, but with emphasis on the society perspective, as this is the main reason for value creation. The results presented are expected to contribute to both academia and the PMPB, as the applicability of BSC can influence management improvement.

Keywords: Balanced Scorecard; Military police; Strategic planning.

\section{INTRODUÇÃO}

As organizações, atualmente, sofrem diversas pressões e modificações advindas do meio externo, a qual estão inseridas, o que exige um maior grau de planejamento e aferição de indicadores de desempenho. Para tanto, a aplicação de ferramentas de gestão está se tornando cada vez mais necessária para que o objetivo organizacional seja alcançado, mantendo e aperfeiçoando o seu funcionamento completo e eficaz.

As instituições do setor público, apesar de apresentarem peculiaridades, também necessitam da adoção de modelos gerenciais adequados que viabilizem o cumprimento de suas atribuições legais, sendo assim, as decisões estratégicas devem ser embasadas em um planejamento preestabelecido, não sendo coerente que suas intervenções tenham apenas influências externas e de caráter emergencial.

Uma das ferramentas gerenciais adaptáveis ao âmbito da administração pública é o Balanced Scorecard - BSC, que é um instrumento de gestão, o qual expressa os objetivos estratégicos em um referencial de análise estruturado, composto por quatro perspectivas: a) financeira; b) Clientes; c) Processos internos; d) Aprendizado e crescimento (Kaplan \& Norton, 1997).

Estratégias eficazes são definidas por meio das características e objetivos organizacionais. O processo de formulação do BSC tem como ponto de partida a definição da missão, visão e valores da organização para que posteriormente seja possível definir quais as melhores estratégias para alcançar os objetivos previstos em cada uma das perspectivas (Fernandes, Furtado \& Ferreira, 2016). Nesse contexto, também é possível a implantação do BSC na área pública, contudo a partir de adaptações nas perspectivas tradicionais ao enfatizar nas especificações da sociedade e demandas das organizações (Gomes, 2006; Bentes, 2011; Taffarel, 2018).

Dentre as instituições do setor público, a Polícia Militar, diante da complexidade da sua missão perante a sociedade, pode desenvolver e se utilizar de ferramentas gerenciais específicas, tais como, Planejamento estratégico, Análise de ambientes, Construção de cenários, BSC, dando a possibilidade de orientar ações, geralmente dinâmicas e urgentes. Assim, o presente artigo apresenta o seguinte problema: Como implantar o BSC como ferramenta estratégica de apoio à decisão, no $1^{\circ}$ batalhão da Polícia Militar da Paraíba?

Diante disso, o presente artigo tem como objetivo geral apresentar uma proposta de implantação do BSC no $1^{\circ}$ batalhão da Polícia Militar da Paraíba. Além de traçar os seguintes objetivos específicos: a) analisar a realidade estratégica da instituição; b) identificar quais os 
pontos de melhorias do batalhão, na visão dos policiais militares, que fazem parte de seu efetivo; c) analisar o plano estratégico atual do batalhão, enfocando a formulação dos objetivos nas quatro perspectivas estabelecidas no BSC e relações de causa e efeito.

Considerando o exposto, a Polícia Militar da Paraíba deve buscar garantir a eficiência dos seus processos e, consequentemente, seus resultados. É nesse intuito, que o presente estudo tem como justificativa a premência da instituição em utilizar ferramentas capazes de vincular diversas variáveis e a partir delas, desenvolver estratégias capazes de entregar os resultados esperados. Dessa forma, faz-se necessário analisar a adaptabilidade do uso do BSC, a fim de averiguar uma possível aplicação da ferramenta. Ademais, o estudo pode embasar ao comando geral da instituição, a adoção do BSC como instrumento de apoio à decisão.

\section{REFERENCIAL TEÓRICO}

\subsection{Balanced Scorecard na Administração Pública e na Polícia Militar}

Neely (1998) definiu a mensuração de desempenho como a ferramenta de quantificar a efetividade e eficiência das ações anteriores, por meio da aquisição, coleta, classificação, análise, interpretação e disseminação dos dados apropriados, criando informações de importância para que as ações preventivas ou corretivas sejam aceitas.

De acordo com Mason e Swanson (1981), a mensuração de desempenho tem um objetivo central na vida das empresas e organizações, com qualquer natureza, seja ela pública ou privada, pequena, média ou grande e com ou sem fins lucrativos. Para os autores supracitados, uma boa mensuração adequada pode diminuir os potenciais problemas da má qualidade ou da falta de dados do mesmo, apesar que as organizações de todos os tipos praticamente, as decisões são tomadas em cima destes dados.

A administração pública como um todo se ressente de reconhecidos problemas de ineficiência e ineficácia. "Apesar da Lei de Responsabilidade Fiscal apresentar um reordenamento das finanças públicas, não apresenta uma visão de longo prazo, especialmente no que diz respeito à conformação estratégica dos órgãos públicos, orientada para elevação consistente de seu desempenho" (Taffarel, 2018, p. 63).

Não obstante, diante da nova ótica da administração pública e da necessidade de melhores planejamentos e mensuração de desempenho, o BSC vem sendo pensado e adaptado para implantação em instituições públicas. No âmbito público, as perspectivas e abordagens podem ser adaptadas com outros nomes e com fins correlatos no objeto público: "orçamento ou sustentabilidade financeira; cidadão ou sociedade; processos internos; aprendizado e inovação ou crescimento funcional" (Rezende, 2015, p. 150).

Kaplan e Norton, criaram o BSC como um sistema de mensuração de desempenho e, diante disso, como um sistema de gestão estratégica. No BSC a comunicação dar-se através de uma estrutura lógica ou causal, apoiada na gestão das metas determinadas, seu alcance ou não, proporcionando aos gestores repor recursos físicos, financeiros e humanos para que possam conseguir os objetivos estratégicos. O BSC é mais que um sistema de mensuração de desempenho, é um tradutor da estratégia e comunicador do desempenho (Kaplan \& Norton, 1997).

O desempenho do BSC em empresas privadas é totalmente voltado à geração de lucro, através do alinhamento de todas as perspectivas, sendo a financeira, que determina as decisões de mensuração (Matias-Pereira, 2018). Já em empresas públicas, a perspectiva cidadão/sociedade, é considerada como a mais importante, pois a gestão pública tem como principal razão de existir a garantia do bem-estar social. Esse setor não possui apenas clientes 
que decidem comprar ou não o serviço, contudo clientes que, compulsoriamente, dão uma contrapartida pela disponibilidade dos serviços públicos, face ao caráter dos mesmos (Teixeira, Cruz \& Fonseca, 2015).

A nova gestão pública também pode ser aplicada nos serviços militares, apesar de se ter algumas restrições, o uso do BSC pode trazer clareza no processo de desenvolvimento de estratégias na segurança pública. A atividade de qualquer serviço policial, como a manutenção da segurança e da ordem pública, a prevenção e redução do crime, a verificação da aplicação da lei, a investigação criminal, entre outras, deve estar na base da elaboração do BSC e do desenvolvimento das suas perspectivas (Gomes, 2006). O quadro a seguir mostra como foi estruturada a aplicação do BSC nas polícias em outros países:

\begin{tabular}{|c|c|l|}
\hline \multicolumn{1}{|c|}{ Instituição } & Países & \multicolumn{1}{c|}{ Estrutura do BSC } \\
\hline SwedishNational Police Board & Suécia & Recursos; Cidadãos; Sucesso; Pessoal. \\
\hline Dumfries e Galloway & Escócia & $\begin{array}{l}\text { Clientes/cidadãos; Processos internos; Aprendizagem; } \\
\text { Finanças. }\end{array}$ \\
\hline $\begin{array}{c}\text { Royal CanadianMounted } \\
\text { Police }\end{array}$ & Canadá & $\begin{array}{l}\text { Clientes e stakeholders; Processos; Pessoas, aprendizagem } \\
\text { e mudança. }\end{array}$ \\
\hline West MerciaConstabulary & Reino Unido & $\begin{array}{l}\text { Satisfação dos Clientes; Desempenho financeiro; } \\
\text { Processos internos; Aprendizagem e crescimento. }\end{array}$ \\
\hline $\begin{array}{l}\text { Qualidade e segurança; Clientes; Sucesso; Eficiência e } \\
\text { Finanças; Inovação e desenvolvimento. }\end{array}$ \\
\hline
\end{tabular}

Quadro 1. Utilização do BSC nas forças policiais

Fonte: Gomes, 2006.

O esforço dispendido para a aplicação do BSC não pode justificar o contínuo adiamento da sua implementação. É necessário o envolvimento das chefias e, essencialmente, uma mudança de cultura relativamente à avaliação do desempenho na Administração Pública (Gomes, 2006, p. 92). No Brasil já foram realizados estudos com propostas de implantação do $B S C$ que demonstraram que a ferramenta pode trazer resultados satisfatórios a polícia militar (Bentes, 2011; Taffarel, 2018).

Segundo Bentes (2011), a construção do $B S C$ de uma empresa pública, como a polícia militar, se torna relevante à medida que evidencia a estratégia mais compreensível e mais clara, além de apresentar o que precisa ser feito para alcançar as melhorias necessárias para o alcance dos resultados que justificam a existência da organização. Outro ponto importante é o papel do próprio governo através do estabelecimento de objetivos e metas gerais para o Estado por meio do planejamento estratégico.

Entretanto, conforme autor supracitado, ainda é papel dos gestores encontrar como a atividade da organização precisa ser deliberada para o futuro e quais as mudanças necessárias para esse fim, que comumente compreende os modos de gerir a corporação.

\section{METODOLOGIA}

O presente estudo se caracterizou por abordagem qualitativa e quantitativa. Quanto ao procedimento, o presente estudo é caracterizado como pesquisa documental. Em relação à natureza do estudo, se enquadra por pesquisa aplicativa, que objetiva gerar conhecimentos para aplicação prática, dirigidos à solução de problemas específicos.

Alinhada à abordagem do presente estudo, foi realizada uma entrevista semiestruturada com o analista criminal da Secretaria de Estado da Segurança e da Defesa Social da Paraíba (SESDS) com intuito de entender a realidade estratégica da instituição. 
Em concordância com os objetivos do estudo, no período de 23/04/2019 a 30/04/2019, aplicou-se questionários com amostragem de 146 dos 645 policiais correspondentes ao $1^{\circ}$ batalhão. A liberação da aplicação se deu através do envio de uma carta de apresentação ao Comando Geral da Polícia Militar da Paraíba, que autorizou a pesquisa. O intuito da coleta e análise dos dados foi identificar o ponto de vista dos policiais militares frente à instituição, na intenção de melhor adequar as estratégias nas perspectivas do BSC. O questionário utilizado foi semiestruturado tricotômico (enquadramento geral, conhecimento estratégico da instituição e avaliação do ambiente organizacional), contento questões de múltipla escolha, abertas e de sim/não.

Para formulação da proposta da implantação do $B S C$ e relações de causa e efeito, além da entrevista e da aplicação do questionário, foi realizado estudo da diretriz institucional e do mapa estratégico que dá suporte a polícia militar a partir desse mapa, foi desenvolvida toda a proposta de implantação da ferramenta.

\section{ANÁLISE DOS DADOS}

\subsection{Diretriz institucional e mapa estratégico SESDS 2015-2024}

O direcionamento da Polícia Militar é definido pela Secretaria de Estado da Segurança e da Defesa Social da Paraíba (SESDS). Sendo assim, o mapa estratégico traz um único alinhamento para o desenvolvimento das ações tanto da polícia militar, quanto da Civil e Corpo de Bombeiros.

O $1^{\circ}$ Batalhão da PMPB é uma unidade operacional que se localizada no Centro da cidade de João Pessoa, capital do Estado da Paraíba. Possuem 645 policiais efetivos, divididos em duas categorias: oficiais (nível estratégico) e praças (nível operacional).

Quanto à missão, a Polícia Militar visa promover e garantir a segurança pública e a defesa social no estado da Paraíba, por meio de ações integradas dos seus órgãos operativos, articuladas com os poderes públicos e com a sociedade, visando à preservação dos direitos fundamentais e uma cultura de paz. No tocante à visão, a entidade pretende ser referência nacional na redução contínua dos índices criminais e na promoção de uma cultura de paz até 2024. Por fim, em relação aos valores, destacou-se: o profissionalismo; comprometimento; legalidade; ética; transparência; proatividade e inovação.

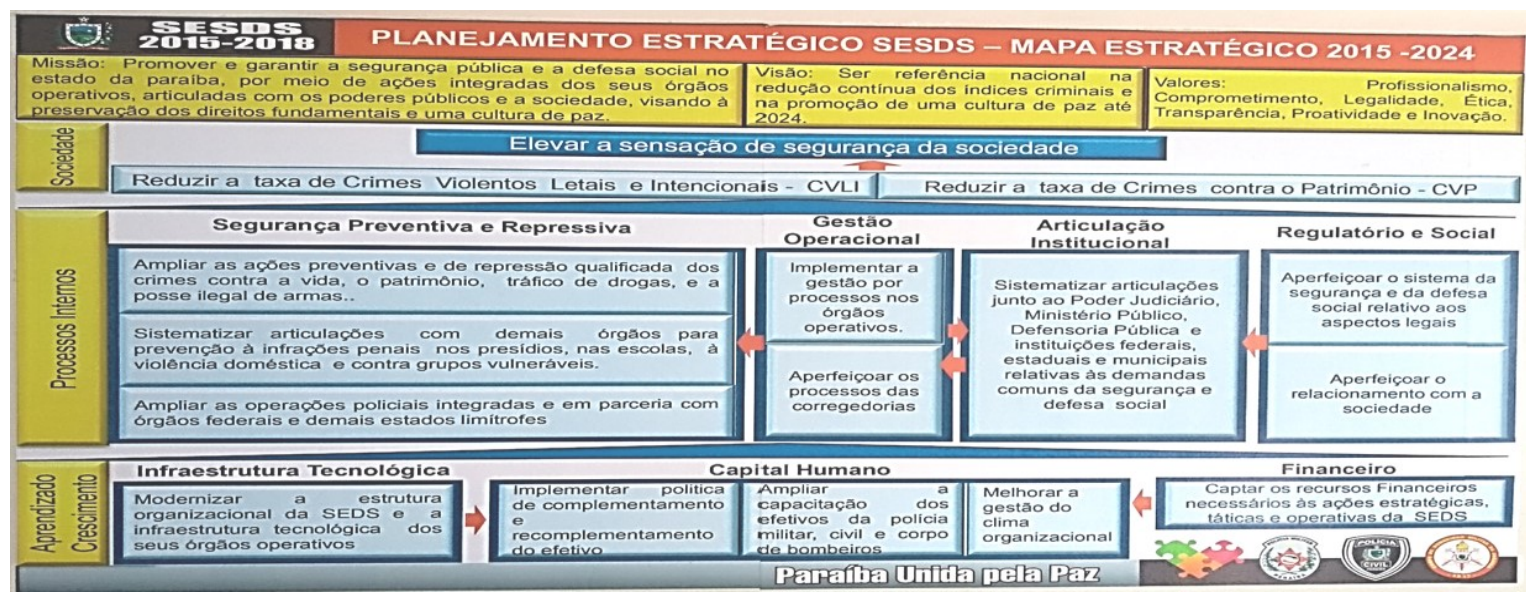

Figura 1. Mapa estratégico do SESDS.

Fonte: Secretaria de Estado da Segurança e da Defesa Social da Paraíba - SESDS, 2019. 
Conforme a Figura 1, o mapa estratégico do SESDS já apresenta uma estrutura base para o desenvolvimento de um Balanced Scorecard, pois declara objetivos nas perspectivas indicadas pelo BSC: clientes (sociedade); processos internos; aprendizado e crescimento e finanças. Através desses objetivos levantados pela secretaria é possível desenvolver metas, indicadores e planos de ação.

\title{
4.2. Análise da entrevista com analista criminal da SESDS
}

Para um maior entendimento do planejamento estratégico da polícia militar da Paraíba e consequentemente do $1^{\circ}$ batalhão, foi realizada entrevista com o Analista Criminal da SESDS. Em questionamento sobre como é estabelecido o planejamento estratégico na PMPB, o analista informou que o planejamento está sendo feito por uma consultoria externa e que ainda não se tem um planejamento estruturado, mas que as ações são desenvolvidas de acordo com o plano estratégico (figura 1) que foi previamente divulgado. Salientou ainda que esse planejamento engloba não apenas as polícias militar, civil e corpo de bombeiros. Segue abaixo trecho da entrevista:

\begin{abstract}
"O Programa Paraíba Unida pela Paz foi instituído em janeiro de 2011 e ao longo desses oito anos, ele foi passando por diversas fases. A primeira fase foi um planejamento operacional, onde foi realizado um breve diagnóstico, estabelecendo uma meta, uma prioridade, que é o indicador dos crimes violentos letais e intencionais - CVLI. Ao longo do tempo esse plano foi sendo executado e monitorado e já no final de 2015 para 2016 começou a construção do planejamento estratégico, mas aí esse planejamento não foi feito só com a secretaria de segurança, foi contratada uma consultoria e essa consultoria ouvindo várias reuniões e acompanhando várias atividades vem desenvolvendo esse trabalho. $O$ que a gente tem é um breve relance do planejamento, um mapa que tá lá na frente, com missão, visão e valores, nossos objetivos, e esse banner tá em vários locais, no centro de educação, Acadepol." (Analista criminal).
\end{abstract}

Atualmente, segundo resposta ao questionamento sobre como é mensurado o desempenho da instituição, o principal indicador de mensuração é o Crime Violento, Letais e Intencionais (CVLI), conforme exposto abaixo:

\footnotetext{
"Nosso desempenho é mensurado por esse indicador, o CVLI, que "tá" amparada pela Portaria local 058/2014 e essa portaria também tem conexão com a Lei 10.327, que institui o prêmio Paraíba Unida pela Paz. Então, semestralmente, a gente faz esse balanço nos territórios, a gente tem através de uma lei complementar, a distribuição do estado em áreas integradas de segurança pública e a gente faz essa mensuração por área e por regiões, além de mensurar também o estado como todo. Então, quando a gente bate essa meta que estava estabelecida em 10\%, a gente consegue obter o que a lei estabelece. A gente calcula a meta em cima do CVLI, comparando o número de homicídios do semestre com o número de homicídios registrados no mesmo semestre do ano anterior." (Analista criminal).
}

Após o estabelecimento da CVLI, os resultados em relação ao atingimento da redução de crimes violentos estão sendo cada vez mais positivos, o que pode demonstrar que estipular metas e indicadores para a instituição pode desenvolver ainda mais o seu potencial ostensivo. Através dessa constatação, foi questionado se havia possibilidade de aplicação do Balanced Scorecard no planejamento da instituição, a resposta segue no trecho a seguir:

"Não chegamos ao nível do BSC ainda, mas porque temos uma dificuldade grande em relação a efetivo em relação a recursos e vale lembrar que esse programa foi 
desenvolvido no período de crise econômica e não se conseguiu desenvolver ainda esse fenômeno geral. Essa visão mais abrangente em relação aos indicadores, a gente ficou realmente no método de gestão só baseado no CVLI." (Analista criminal).

A Paraíba foi destaque na redução de homicídios no primeiro quadrimestre de 2019 , tendo uma redução de $22 \%$ em relação ao índice do ano anterior, apesar do resultado, sabe-se que é necessário superar obstáculos advindos do ambiente interno e externo. Quando questionado em relação aos pontos críticos em relação a esse indicador, foi levantado os seguintes pontos:

\begin{abstract}
"Ainda temos uma dificuldade de recurso e de efetivo que é um ponto que a gente tem convivido apesar do esforço pra fazer mais com o mesmo, mas chega um momento que fica inviável, sobretudo quando se tem muitas demandas como eventos e tal, ai faltam recursos para cumprir com o planejamento, a gente acaba sendo demandando e não tomando a iniciativa de se orientar pelo próprio planejamento e outro problema específico também que é uma ameaça sempre presente, é o próprio crime organizado." (Analista criminal).
\end{abstract}

Dentro do plano estratégico também é apresentado o indicador Crimes Violentos contra o Patrimônio (CVP), que são referentes a crime contra o patrimônio, que apesar de não ser destaque como o CVLI, vem sendo trabalhado, para que, se tenha um melhor acompanhamento.

\footnotetext{
"Nesse na, a gente estabeleceu uma Portaria, agora em 2019, que fez uma mudança na metodologia do CVP, primeiro que o CVP ele era anteriormente monitorado CVP de João Pessoa e Campina Grande até porque são as cidades que concentram mais da metade de CVP no estado. Agora a gente expandiu esse monitoramento $e$ fez metodologicamente um desmembramento do CVP e criou um novo indicador patrimonial, porque o que é que ocorre? A gente percebeu que de cada cem roubos do CVP que anteriormente aconteciam, a gente tinha $70 \%$ do roubo de celular, que era roubo comum a pessoa na rua, porém a gente reconhece que a grande maioria desses casos não são comunicados a polícia, então a gente não tinha uma confiabilidade de saber se o CVP estava realmente diminuindo ou se era o sub registro que estava aumentando e vice versa, então a gente reconhecendo essa grande problemática, foi criado o SIVA - Subtração ilegal de veículos automotivos, e vai agregar o roubo de moto, de carro, o furto de moto e furto de carro, como também caminhão e ônibus, qualquer veículo." (Analista criminal).
}

Apesar da abrangência desses dois indicadores, foram questionadas quais outras metas poderiam ser estipuladas na instituição:

"Na portaria 026/2019 incluímos mais três metas. A gente criou um indicador novo de ALT - Acidentes letais de trânsito, pois se percebeu que não adiantava cuidar só da valorização da vida no sentido da violência criminal, então a gente criou uma meta de redução de $10 \%$ no número de vitimas de acidentes letais no trânsito e também vai ter como fonte o núcleo de medicina legal onde são registradas todas as mortes por acidente de trânsito. A segunda meta que a gente estabeleceu foi justamente do novo indicador chamado CIBAN - Crimes contra instituições bancárias, que aí como também é um fenômeno de grande repercussão, o nível de sub registro é muito baixo. E como eu te falei, a gente criou também uma meta de redução de 10\%, assim de como é do CVLI pra o SIVA, que a gente consegue medir de uma forma mais plausível e estabeleceu também uma redução de $10 \%$ nos furtos e roubos de carros e motos." (Analista criminal). 
Sendo de suma importância o alinhamento estratégico em todos os níveis da instituição, questionou-se como acontece a disseminação da missão, visão, valores e objetivos:

\begin{abstract}
"É um desafio, temos uma dificuldade grande, porque a gente "tá" falando aí, de dez mil servidores, na verdade mais de dez, dez mil aproximadamente só na PM, vamos pensar assim, quando a gente tem um comite gestor aqui, que é comandado pelo secretário, comandante geral, delegado geral, ele tem um planejamento da missão, mas até que essa missão seja executada lá na ponta, existe toda uma cadeia, um processo, que é extremamente dificultoso se transmitir a mesma ideia, os mesmos princípios e os mesmos valores. Como a instituição é muito grande, esse ponto tem que ser muito trabalhado dentre toda essa cadeia hierárquica, passada ao comandante geral, comandantes de batalhões e todos tem que realmente empreender toda a filosofia da polícia." (Analista criminal).
\end{abstract}

Em relação a como são estipulados orçamentos para os batalhões e se os comandantes são avaliados pelo seu cumprimento, verificou-se que:

\begin{abstract}
"A polícia militar tem autonomia financeira, então, ela tem uma unidade financeira própria, diferentemente da secretaria e dentro da gestão financeira da polícia militar, cada batalhão vai ter um efetivo muito diferenciado, tem batalhões com 400 homens e batalhões com cerca de 100 homens, então, isso repercute totalmente no número de viaturas, na área que abrange, então, o orçamento é diferenciado pra cada unidade. O montante de verba que eles podem gerir é o chamado verba de custeio, então, cada batalhão tem o seu custeio conforme sua proporção e dimensão. Se os comandantes são avaliados, foge da minha competência saber como é a gestão em relação a esse aspecto." (Analista criminal).
\end{abstract}

Por fim, em relação a existência de prazos regulares para treinamentos, o analista criminal apontou que:

"Tem um prazo regular. Os obrigatórios são para quem vai subir de cargo, mas tem os não obrigatórios que são periodicamente feitos com uma frequência inclusive muito maior, mas são de áreas especializadas dentro da instituição." (Analista criminal).

De modo complementar à visão do analista criminal da SESDS, verificou-se na sequência quais os pontos de melhorias do batalhão, na visão dos policiais militares, que fazem parte de seu efetivo.

\title{
4.3. Análise do questionário aplicado com os policiais militares
}

O efetivo na polícia militar é dividido em duas categorias, oficiais e praças. Sendo os oficiais alocados em atividades estratégicas e os praças em atividades operacionais. Apesar dessa distinção de atividades, faz-se necessário a divulgação dos objetivos de maneira homogênea. A partir da correlação dos dados, será possível verificar se há esse alinhamento estratégico.

A partir da categorização, conseguiu-se aplicação do questionário com várias patentes, como a aplicação foi maior em policiais praças, consequentemente se obteve um maior número de respondentes cabo, $21 \%$. Contudo, nesse quesito, as caracterizações ficaram bem heterogêneas, o que pode oferecer a pesquisa uma análise do conhecimento estratégico em diversos níveis hierárquicos. 
$\mathrm{Na}$ amostragem, os maiores números de respondentes estão na faixa etária de 45 a 50 anos de idade. A representatividade de policiais mais velhos foi bem maior, o que consequentemente, oferece uma amostragem de policiais com maior tempo de atuação. A partir desse dado, pode-se supor que o $1^{\circ}$ batalhão apresenta um efetivo mais experiente e com um bom grau de conhecimento em relação à instituição.

Tendo em vista que a polícia militar apresenta um efetivo mais homogêneo em relação à sexualidade, a amostragem apresenta $96 \%$ de policiais do sexo masculino e apenas $4 \%$ de policiais do sexo feminino.

Identificou-se ainda que $54 \%$ dos policiais participantes da pesquisa possuem escolaridade a nível médio, enquanto, $36 \%$ são graduados e $10 \%$ pós-graduados. Correlacionando esses dados com a efetivação, é possível verificar que em relação aos oficiais $44 \%$ são graduados, $39 \%$ pós-graduados e $17 \%$ possuem escolaridade média. Já em relação aos praças, $66 \%$ apresentam escolaridade nível médio e 34\% graduados, não havendo pósgraduados na amostragem dessa efetivação. É plausível um maior nível de escolaridade dos oficiais por causa de suas demandas estratégicas e suas posições de comando na instituição. Porém, é possível verificar considerável número de graduados nos policiais praças, elevando o nível geral da escolaridade da instituição, o que tende a fortalecer o batalhão.

A segunda parte do questionário aplicado foi referente ao conhecimento do efetivo em relação ao planejamento estratégico do batalhão. Com $95 \%$ de respostas positivas sobre o conhecimento da missão e $84 \%$ sobre a disseminação evidenciou-se que a missão é bem definida e propagada por todo o batalhão, o que é bem satisfatório, pois é através desse conhecimento que os objetivos estratégicos ficam claros para todo efetivo, independente do seu nível hierárquico.

Em relação ao conhecimento da visão da PM e seus objetivos, verificou-se que apesar do conhecimento e propagação da missão ser satisfatório, o mesmo não ocorre com a visão institucional, pois esse conhecimento apenas atinge 30\% do efetivo. Considerando somente os oficiais, $50 \%$ responderam que teriam consciência dessa visão para os próximos anos, o que pode ser um fator preocupante, já que realizam atividades estratégicas e teoricamente devem desenvolver ações, através desse aspecto. Atendendo apenas os praças, esse número é ainda menor, 24\% desse efetivo afirmou conhecer essa visão.

Contrariando o questionamento anterior, a respeito da consciência dos objetivos, atingiu $70 \%$ de respostas positivas. Pode-se afirmar, que os objetivos são definidos e propagados, mas não necessariamente estão alinhados com a visão institucional.

Em relação ao conhecimento dos planos de ação, não houve unanimidade em nenhuma das opções de resposta, o que pode nos alertar para o fato de que algumas equipes não estejam planejando ações, mas agindo de maneira reativa à suas demandas. Assim, mesmo com o dinamismo da atividade da polícia militar, é possível desenvolver planos de forma estratégica, para que os objetivos sejam alcançados e os riscos não ameacem as atividades da instituição (Gomes, 2006; Bentes, 2011). Alinhado com a entrevista realizada, houve concordância na informação da instituição possuir metas a serem alcançadas, tendo $92 \%$ de afirmações positivas.

Apesar da mensuração de desempenho ser baseada apenas na CVLI, os respondentes afirmam que a mesma seja totalmente ou parcialmente suficiente para avaliação e controle da instituição, $42 \%$ afirmam que sim e $30 \%$ que parcialmente. Sendo ainda considerada atingível por $52 \%$ da amostragem.

$\mathrm{Na}$ sequência verificou-se que há uma geração de conhecimento, através das ocorrências e correlacionando esses dados com a efetivação, oficial e praça, verifica-se que o 
estudo é realizado mais pela área estratégica, pois dos $29 \%$ de respostas negativas, $27 \%$ são de policiais praças, operacionais.

Considerando o alto grau de periculosidade e dinamismo da atividade da instituição, apresenta ponto de melhoria para o desenvolvimento profissional do seu efetivo, $34 \%$ dos respondentes afirmaram não receber treinamento para realização de suas demandas e $40 \%$ afirmam, que recebem de maneira parcial. Realizando correlações é possível verificar que há concordância dessas afirmações nas duas categorias, oficiais e praças.

Avaliando os recursos e o suporte operacional, a maior parte da amostra, $48 \%$, apontam que apenas recebem esse suporte de maneira parcial, tendo apenas 33\% de respostas positivas para esse questionamento. A avaliação do conhecimento da estratégia fornecida foi satisfatória, $40 \%$ dos respondentes afirmam que o conhecimento é suficiente para o desempenho da sua função, e $42 \%$ afirmam ter parcialmente.

A terceira parte do questionário aplicado foi referente ao clima organizacional e suas possíveis melhorias. As respostas referentes ao clima organizacional correspondem a $51 \%$ de afirmações positivas e $37 \%$ avaliaram que esse clima é parcialmente favorável. O sentimento de valorização do trabalho acompanha a mesma satisfação, apresentando $41 \%$ de respostas positivas e $41 \%$ afirmam que a valorização ocorre de maneira parcial.

As respostas para o questionamento sobre a abertura recebida para compartilhamento de conhecimentos e experiências em reuniões foram bem homogêneas, 37\% afirmam que conseguem compartilhar seus conhecimentos e experiências, $30 \%$ conseguem de maneira parcial e 33\% afirmam não conseguir, desses 31\% são da categoria praça. Sendo assim, constata-se, que os oficiais têm mais abertura para compartilhar seus conhecimentos em reuniões.

Em relação ao recebimento de feedbacks, $41 \%$ afirmam não receber as devidas avaliações, $32 \%$ afirmam receber e $27 \%$ recebem parcialmente. Da porcentagem total das respostas negativas, $32 \%$ são policiais de categoria praça, através dessa correlação, pode-se concluir que os oficiais têm um maior acompanhamento da instituição.

Dos policiais que afirmaram receber feedbacks, $72 \%$ concordam com suas avaliações. $\mathrm{O}$ último questionamento feito aos policiais militares foi em caráter subjetivo, onde deveria ser descrito os pontos de melhoria que podem aumentar o desempenho tanto individual, quanto em equipe. Como a questão foi aberta, nem todos responderam a esse questionamento, sendo alcançado $84 \%$ de respostas.

No tocante à opinião dos respondentes, sobre o que precisa ser melhorado na instituição para aumentar o desempenho tanto individual, quanto em equipe, percebeu-se que o reconhecimento foi o fator mais mencionado, atingindo o percentual de $31 \%$, desses, $26 \%$ foram respostas dos respondentes da categoria praça. Esse fator pode ser atrelado ao percentual da insatisfação, o qual ocorre pela diferença de tratamento recebido pelos oficiais versus praças, que atingiu $5 \%$ das respostas. O segundo fator de maior reclamação foi a remuneração, porém já é de conhecimento do efetivo que essa questão não é de decisão dos comandos, mas sim, do governo e suas diretrizes.

\subsection{Formulação do BSC de acordo com os dados levantados}

\subsubsection{Perspectiva sociedade}

Por se tratar de instituição pública, a perspectiva sociedade é a mais importante na correlação de indicadores no Balanced Scorecard, conforme Tabela 1. Através do mapa estratégico e das informações levantadas através da entrevista e aplicação de questionários, é 
possível reconhecer que existe um bom conhecimento e acompanhamento das principais ocorrências e que já estão sendo criadas metas e indicadores para o alcance dos objetivos. Entretanto, observa-se que o indicador CVLI, é o único que vem sendo usado para mensuração de desempenho e reconhecimento na instituição. Para uma resposta mais eficaz nessa perspectiva, faz-se necessário colocar em prática os indicadores postos na portaria 026/2019.

Tabela 1

Perspectiva Sociedade

\begin{tabular}{|c|c|c|c|}
\hline Objetivo Estratégico & Estratégia & $\begin{array}{c}\text { KPI - Key Performance } \\
\text { Indicators } \\
\end{array}$ & Meta \\
\hline Redução da CVLI & $\begin{array}{ll} & \text { Adequação de } \\
\text { policiamento } \\
\text { ostensivo E } \\
\text { preventivo; } \\
\text { Realização de } \\
\text { ações integradas. }\end{array}$ & $\begin{array}{l}\text { Quantidade de } \\
\text { ocorrências registradas. }\end{array}$ & $\begin{array}{l}\text { Redução de } 10 \% \text { em } \\
\text { relação ao ano anterior }\end{array}$ \\
\hline Redução do CVP & $\begin{array}{ll}\text { - } & \text { Adequação de } \\
\text { policiamento } \\
\text { ostensivo e } \\
\text { preventivo; } \\
\text { - } \quad \text { Realização de } \\
\text { ações integradas. }\end{array}$ & $\begin{array}{l}\text { Quantidade de } \\
\text { ocorrências registradas. }\end{array}$ & $\begin{array}{l}\text { Redução de } 10 \% \text { em } \\
\text { relação ao ano anterior }\end{array}$ \\
\hline Redução do SIVA & $\begin{array}{l}\text { Adequação de } \\
\text { policiamento } \\
\text { ostensivo e } \\
\text { preventivo; } \\
\text { Realização de } \\
\text { ações integradas. }\end{array}$ & $\begin{array}{l}\text { Quantidade de } \\
\text { ocorrências registradas. }\end{array}$ & $\begin{array}{l}\text { Redução de } 10 \% \text { em } \\
\text { relação ao ano anterior }\end{array}$ \\
\hline Redução do CIBAN & $\begin{array}{ll}\text { - } & \text { Adequação de } \\
\text { policiamento } \\
\text { ostensivo e } \\
\text { preventivo; } \\
\text { - } \quad \text { Realização de } \\
\text { ações integradas. }\end{array}$ & $\begin{array}{l}\text { Quantidade de } \\
\text { ocorrências registradas. }\end{array}$ & $\begin{array}{l}\text { Redução de } 10 \% \text { em } \\
\text { relação ao ano anterior }\end{array}$ \\
\hline Redução do ALT & $\begin{array}{l}\text { Adequação de } \\
\text { policiamento } \\
\text { ostensivo e } \\
\text { preventivo; } \\
\text { Realização de } \\
\text { ações integradas. }\end{array}$ & $\begin{array}{l}\text { Quantidade de } \\
\text { ocorrências registradas }\end{array}$ & $\begin{array}{l}\text { Redução de } 10 \% \text { em } \\
\text { relação ao ano anterior }\end{array}$ \\
\hline $\begin{array}{l}\text { Aproximação e } \\
\text { reconhecimento da } \\
\text { sociedade }\end{array}$ & $\begin{array}{ll}\text { - } & \text { Aumento de } \\
\text { interação nas } \\
\text { redes sociais da } \\
\text { instituição; } \\
\text { - Atualização do } \\
\text { site, expondo a } \\
\text { missão, visão e } \\
\text { valores, além de } \\
\text { atualização de } \\
\text { troca de comandos } \\
\text { e conquistas. }\end{array}$ & $\begin{array}{l}\text { Índice de interações nas } \\
\text { redes sociais; } \\
\text { Número de participação } \\
\text { da sociedade em } \\
\text { elucidação de casos }\end{array}$ & $\begin{array}{c}\text { Aumento de } 5 \% \text { de } \\
\text { interações mensais } \\
\text { Aumento de } 10 \% \text { no } \\
\text { percentual dos crimes } \\
\text { elucidados com a } \\
\text { participação da sociedade } \\
\text { em relação ao ano } \\
\text { anterior }\end{array}$ \\
\hline
\end{tabular}

Fonte: Elaborada pelos autores, 2019. 
A partir das estratégias levantadas é possível desenvolver planos de ação que atenda a demanda do batalhão e as suas peculiaridades. Por não ser de decisão do comando o aumento de efetivo, mas sim, do governo e pela restrição orçamentária, o que se pode planejar é uma programação linear que traga uma distribuição de efetivo e frota adequada para o atendimento dessas ações.

Além dos índices que estão diretamente ligados a ocorrências, a aproximação da sociedade pode ser um ponto chave de sucesso. E para que isso ocorra é necessário que haja clareza em relação à missão institucional através das redes sociais e sites, bem como, as ações sociais que já são desenvolvidas pela PMPB podem ser divulgadas em tempo real de uma maneira mais abrangente, aumentando assim, as interações.

A sociedade através dessa aproximação pode se sentir mais confortável e engajada a auxiliar no desfecho de investigações criminais de forma anônima, que é um meio já existente de comunicação.

\subsubsection{Perspectiva processos internos}

No que se refere à perspectiva de processos internos, mediante Tabela 2, um dos pontos que mais preocupam os dirigentes da instituição é a disseminação de seus objetivos por toda a tropa, de uma maneira que se tenha um total alinhamento estratégico. Nesse sentido, dentro dessa perspectiva é possível desenvolver um evento anual de alinhamento estratégico, voltado para todo o efetivo, oficiais e praças, onde os direcionamentos e materiais de apresentação devem ser repassados do comando geral aos comandantes de batalhões e esses realizem o evento com seu efetivo.

Tabela 2

Perspectiva Processos Internos

\begin{tabular}{|c|c|c|c|}
\hline Objetivo Estratégico & Estratégia & $\begin{array}{c}\text { KPI - Key Performance } \\
\text { Indicators }\end{array}$ & Meta \\
\hline Divulgação da estratégia & $\begin{array}{c}\text { Desenvolver evento anual } \\
\text { de alinhamento } \\
\text { estratégico. }\end{array}$ & $\begin{array}{l}\text { Quantidade de efetivo } \\
\text { participante }\end{array}$ & Atingir todo o efetivo \\
\hline $\begin{array}{l}\text { Sistematizar articulações } \\
\text { com demais órgãos para } \\
\text { prevenção a infrações } \\
\text { penais nos presídios, nas } \\
\text { escolas, à violência } \\
\text { doméstica e contra grupo } \\
\text { vulneráveis. }\end{array}$ & $\begin{array}{l}\text { Desenvolver projetos e } \\
\text { ações integradas com as } \\
\text { áreas respondentes ao } \\
\text { SESDS e órgãos } \\
\text { correlatos. }\end{array}$ & $\begin{array}{c}\text { Número de projetos e } \\
\text { ações }\end{array}$ & $\begin{array}{c}\text { Aumentar em } 10 \% \text { o } \\
\text { número de ações } \\
\text { integradas em relação ao } \\
\text { número das ações } \\
\text { isoladas. }\end{array}$ \\
\hline $\begin{array}{l}\text { Criação de processos } \\
\text { organizacionais }\end{array}$ & $\begin{array}{l}\text { Desenvolvimento de } \\
\text { fluxogramas e check list } \\
\text { para cada atividade } \\
\text { interna. }\end{array}$ & $\begin{array}{l}\text { Número de atividades } \\
\text { atingidas }\end{array}$ & $\begin{array}{l}\text { Processos para todas as } \\
\text { demandas internas }\end{array}$ \\
\hline $\begin{array}{l}\text { Criação de equipes de } \\
\text { trabalho voltadas à } \\
\text { inovação }\end{array}$ & $\begin{array}{l}\text { Selecionar pessoas de } \\
\text { diversas equipes para } \\
\text { desenvolvimento de } \\
\text { inovações que agilizem } \\
\text { os processos internos. }\end{array}$ & $\begin{array}{l}\text { Números de inovações } \\
\text { Taxa de sucesso } \\
\text { Redução de custo }\end{array}$ & $\begin{array}{l}\text { Obter no mínimo } 60 \% \text { de } \\
\text { aprovação da inovação } \\
\text { na instituição } \\
\text { Redução anual de custos } \\
\text { em } 10 \%\end{array}$ \\
\hline
\end{tabular}

Fonte: Elaborada pelos autores, 2019.

Por saber da impossibilidade da realização do evento em um único dia, o mesmo pode ser realizado em dias alternados, dentro de um único mês, repartindo as equipes de operação, 
tendo o cuidado de não interferir nas demandas. Outro ponto de destaque, é a criação da equipe de inovação, que poderá selecionar policiais de diversas equipes e patentes para o desenvolvimento de ideias que tragam agilidade nas operações e redução de custos aos processos internos.

\subsubsection{Perspectiva aprendizagem e crescimento}

Conforme Tabela 3, na perspectiva de aprendizagem e crescimento foi identificado oportunidades de melhorar o clima organizacional, através de políticas de reconhecimento, que têm o intuito de reconhecer o servidor por boas ações e práticas; definição de prazos regulares de realização de treinamento e capacitação e a criação de um programa de inscrição de ideias, que ofertaria a oportunidade do policial, oficial ou praça, expor suas ideias e participar da sua implantação, junto a equipe de inovação sugerida na perspectiva de processos internos em caso de aprovação.

Tabela 3

Perspectiva Aprendizagem e Crescimento

\begin{tabular}{l|c|c|c}
\hline \multicolumn{1}{c}{ Objetivo Estratégico } & \multicolumn{1}{c}{ Estratégia } & $\begin{array}{c}\text { KPI - Key Performance } \\
\text { Indicators }\end{array}$ \\
\hline $\begin{array}{l}\text { Política de } \\
\text { reconhecimento }\end{array}$ & $\begin{array}{c}\text { Reconhecer o servidor } \\
\text { por boas ações e práticas } \\
\text { através de entrega de } \\
\text { PINS colecionáveis. }\end{array}$ & $\begin{array}{c}\text { Grau de satisfação em } \\
\text { trabalhar na instituição - } \\
\text { aplicação de pesquisa } \\
\text { anual para mensuração }\end{array}$ & $\begin{array}{c}\text { Aumentar o grau de } \\
\text { satisfação em 10\% ao } \\
\text { ano }\end{array}$ \\
\hline $\begin{array}{l}\text { Ampliação de } \\
\text { capacitação e treinamento }\end{array}$ & $\begin{array}{c}\text { Definir prazos para } \\
\text { realização de } \\
\text { treinamentos teóricos e } \\
\text { operacionais. }\end{array}$ & $\begin{array}{c}\text { Avaliação média do } \\
\text { aprendizado }\end{array}$ & $\begin{array}{c}\text { Realizar pelo menos um } \\
\text { treinamento teórico e } \\
\text { prático com } 100 \% \text { do } \\
\text { efetivo. }\end{array}$ \\
\hline $\begin{array}{l}\text { Criação de um programa } \\
\text { de inscrição de ideias }\end{array}$ & $\begin{array}{c}\text { Ofertar a oportunidade de } \\
\text { o servidor expor suas } \\
\text { ideias e participar da sua } \\
\text { implantação em caso de } \\
\text { aprovação. }\end{array}$ & $\begin{array}{c}\text { Quantidade de ideias } \\
\text { registradas }\end{array}$ & $\begin{array}{c}\text { Aumentar a quantidade } \\
\text { de ideias registradas e } \\
\text { aprovadas em } 10 \% \text { ao } \\
\text { ano. }\end{array}$ \\
\hline
\end{tabular}

Fonte: Elaborada pelos autores, 2019.

\subsubsection{Perspectiva financeira}

Por fim, conforme Tabela 4, a perspectiva financeira, que só pode ser mensurada, através do cumprimento das restrições orçamentárias. Por ser instituição pública e por não ter autonomia, na realização de investimentos em projetos, a perspectiva financeira vai apenas mensurar o desempenho em relação ao cumprimento do orçamento em relação às despesas do batalhão.

Tabela 4

Perspectiva Financeira

\begin{tabular}{c|c|c|c}
\hline Objetivo Estratégico & Estratégia & $\begin{array}{c}\text { KPI - Key Performance } \\
\text { Indicators }\end{array}$ & Meta \\
\hline $\begin{array}{c}\text { Cumprir restrição } \\
\text { orçamentária }\end{array}$ & $\begin{array}{c}\text { Enquadrar as } \\
\text { necessidades de custeios } \\
\text { dentro dos limites do } \\
\text { orçamento. }\end{array}$ & $\begin{array}{c}\text { Percentual do previsto x } \\
\text { realizado }\end{array}$ & $\begin{array}{c}\text { Manter desvio de } \\
\text { orçamento previsto em } \\
\text { até 5\% para mais ou para } \\
\text { menos. }\end{array}$ \\
\hline
\end{tabular}

Fonte: Elaborada pelos autores (2019). 
Dessa forma, após determinação de cada perspectiva será possível sugerir possíveis relações de causa e efeito, relevando uma relação mútua de cooperação através dos objetivos e metas, ambas evidenciadas no tópico a seguir.

\subsection{Interligações do BSC}

O esquema disposto abaixo demonstra que o cumprimento da meta da perspectiva financeira pode impactar na perspectiva crescimento, mais especificamente no programa de ideias, pois implantação de novas ideias tem como ponto de restrição o seu custo benefício. Essa perspectiva também apresenta impactos nos processos internos, pois algumas ações para divulgação da estratégia podem ocasionar despesas. Além disso, com o provável efeito causado na sistemática de articulações, todas as metas da perspectiva sociedade pode ser impactadas pela restrição financeira.

A perspectiva crescimento apresenta três objetivos: política de reconhecimento, capacitação e treinamento e o programa de ideias. A política de reconhecimento pode auxiliar nos programas de ideias, pois quanto maior for a satisfação do efetivo, maior será seu engajamento em solucionar problemáticas, consequentemente seu interesse em fazer parte do programa poderá aumentar. A capacitação e treinamento também pode influenciar no programa através do conhecimento e clareza que podem ser adquiridos. Além disso, essa capacitação pode trazer vantagens frente a criação de processos, que faz parte da perspectiva processos internos, contribuindo para sua otimização.

$\mathrm{Na}$ perspectiva processos internos foram elencados os seguintes objetivos: divulgação da estratégia; sistematização de articulações; criação de processos e criação de equipe de inovação. A divulgação da estratégia tem impacto direto com todos os objetivos da perspectiva sociedade, pois é esse conhecimento que irá servir de guia para todo o efetivo. A sistemática de articulações tem impacto direto tanto com as perspectivas sociedade, quanto com a financeira, já que esse objetivo deve dar suporte as ações da maneira mais eficaz possível, atendendo as restrições orçamentárias, pois um processo otimizado reduz custos e atende bem as demandas.

A perspectiva mais importante para instituição é a perspectiva sociedade, por isso é a que mais recebe suporte e se apresenta na parte superior do esquema, ademais, é a que reflete a missão da instituição, é a sua razão de existir. O atingimento dos objetivos dispostos nela, além de sinalizar que a estratégia está sendo bem implantada, pode impactar positivamente na sua perspectiva financeira. A seguir é demonstrado todo o esquema de causa e efeito da implantação dessa proposta de BSC para o batalhão: 


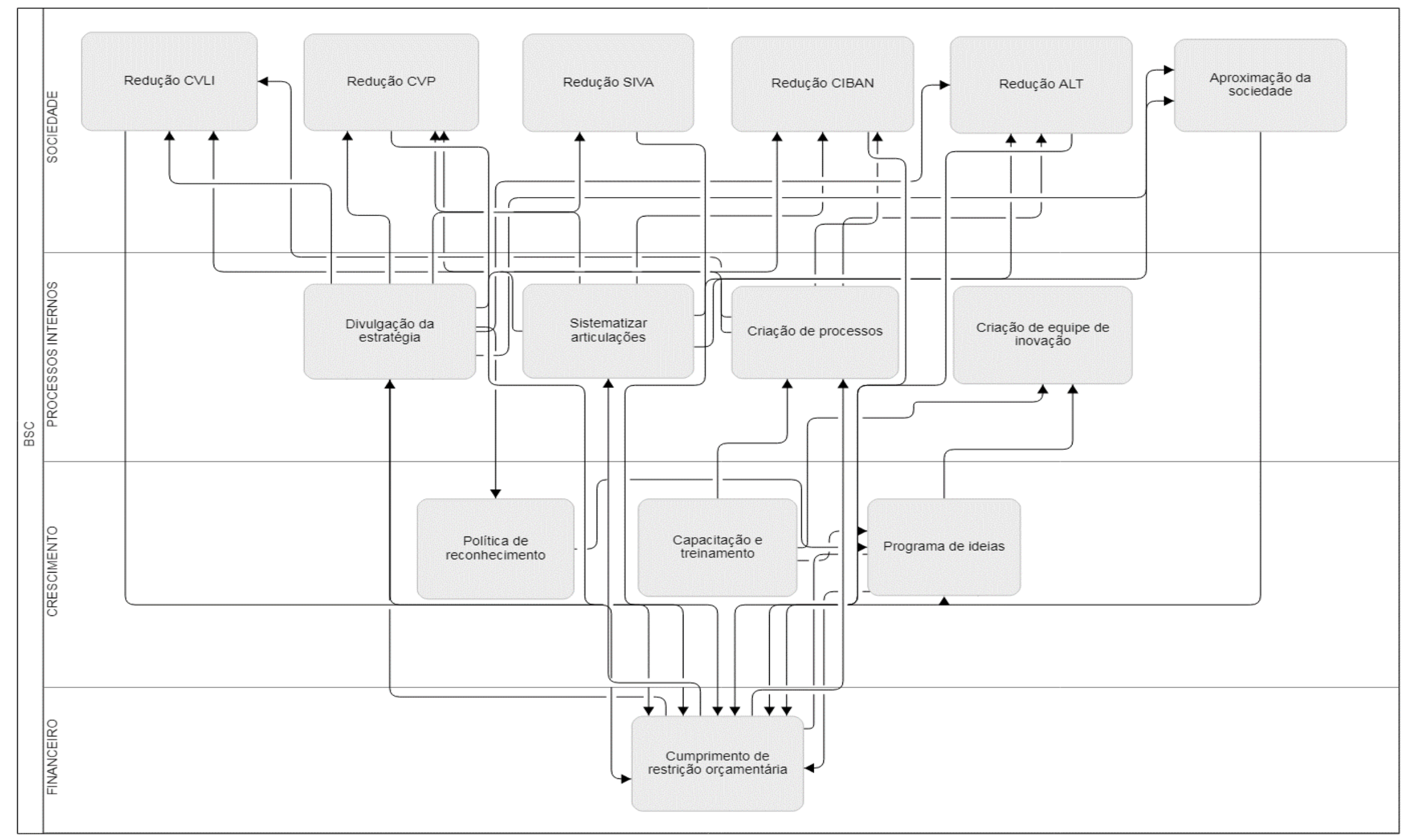




\section{CONSIDERAÇÕES FINAIS}

O artigo teve como objetivo geral apresentar uma proposta de implantação do $B S C$, no $1^{\circ}$ batalhão da PMPB e para seu alcance foram determinados objetivos específicos: a) analisar a realidade estratégica da instituição; b) identificar quais os pontos de melhorias do batalhão na visão dos policiais militares que fazem parte de seu efetivo; c) analisar o plano estratégico atual do batalhão, enfocando a formulação dos objetivos nas quatro perspectivas estabelecidas no $B S C$ e relações de causa e efeito.

Para o alcance do primeiro objetivo específico foi realizada uma entrevista semiestruturada com o analista criminal da Secretaria de Estado da Segurança e da Defesa Social da Paraíba (SESDS). Com isso, foi possível entender que a polícia militar não possui um planejamento próprio, mas que segue um alinhamento da Secretaria de Estado da Segurança e da Defesa Social da Paraíba, que define a missão, visão, valores e objetivos tanto para a PMPB, da mesma forma para a polícia civil e corpo de bombeiros. Importante salientar que a secretaria ainda não possui um planejamento estratégico estruturado, mas o mesmo é desenvolvido por uma consultoria externa que vem acompanhando as reuniões e as atividades para conclusão desse trabalho. Contudo, já foi disponibilizado o quadro estratégico que dispõe da missão, visão, valores e objetivos propostos até 2024 .

Ter esse planejamento alinhado com as demais instituições respondentes à secretaria é um fator positivo, pois os objetivos são uniformes, o que difere são as atividades e contribuições de cada instituição no atingimento dos mesmos. Analisando o quadro estratégico existente, é possível verificar que o planejamento estratégico é construído através de moldes, que atendem a uma formulação do $B S C$, trazendo objetivos, ainda que de maneira generalista, nas perspectivas: sociedade, processos internos, aprendizagem e crescimento, e perspectiva financeira. Para o desenvolvimento de uma estratégia de mensuração de desempenho com o $B S C$ se fez necessário analisar os pontos críticos das atividades que estão envolvidas no alcance de cada objetivo e desenvolver métricas de desempenho.

$\mathrm{Na}$ intenção de atingir o segundo objetivo específico do estudo foi realizada aplicação de questionários com amostragem de 146 policiais que respondem ao $1^{\circ}$ batalhão da polícia militar da paraíba. Através da análise de dados dessa aplicação, obteve-se respostas em relação ao enquadramento geral, conhecimento estratégico da instituição e clima organizacional. A partir disso, podemos destacar que o efetivo possui um bom conhecimento da missão, porém, não compreende em sua totalidade, a visão e os objetivos estratégicos. Outro ponto de destaque é o apontamento em relação a necessidade de se ter mais treinamentos para realização de atividades operacionais.

Com isso, verificou-se que a instituição precisa ser guiada por objetivos e metas claras, sendo necessário que se haja um alinhamento estratégico e que essa condução ultrapasse as barreiras expostas pelo ambiente interno e externo. É perceptível, através da pesquisa, que a gestão nos últimos anos vem se modernizando, na administração e nas formas de se conduzir, e que o $B S C$ pode alavancar ainda mais os resultados da instituição.

A partir das informações obtidas através da entrevista, questionários aplicados e análise do mapa estratégico atual da secretaria, foi possível desenvolver o $B S C$ e relações de causa e efeito, traçando estratégias e métricas para todas as perspectivas, atendendo o terceiro objetivo específico. Por se tratar de uma instituição pública, a perspectiva financeira não é a razão principal da criação de valor, mas os objetivos da perspectiva sociedade, ficando assim no topo do quadro estratégico.

O $B S C$ cria uma relação de causa e efeito entre os objetivos e nesse caso foi possível verificar, que não há um sentido unilateral nessas correlações. Assim, o atingimento de meta 
em qualquer uma das perspectivas gerará efeitos positivos em outras, bem como, o não atingimento irá gerar efeitos negativos nas demais. Com isso, os planos de ação devem se apresentar em concordância ao alcance da estratégia.

Diante do exposto, conclui-se que o objetivo geral do presente estudo foi alcançado, sendo esperado, que os resultados aqui apresentados contribuam, tanto para o meio acadêmico, como para a PMPB, visando a melhoria de gestão. Dentre as limitações do estudo, a maior dela foi com relação à metodologia aplicada, por meio de questionário, pois não é possível encontrar considerável número de efetivo no batalhão, já que as equipes estão sempre envolvidas em operações e realizando policiamento preventivo.

Dessa maneira, para realização de pesquisas futuras, pode-se sugerir: a replicação da pesquisa com uma amostra maior, que possa abranger o batalhão como todo, aprofundando os resultados e desenvolvendo indicadores para as demais atividades críticas. Além da possibilidade da replicação em todos os batalhões da polícia militar do estado da Paraíba.

\section{REFERÊNCIAS}

Bentes, G. P. (2011) Utilização do Balanced Scorecard na Gestão Pública: Um estudo de caso na polícia militar do estado do Rio Grande do Norte. Dissertação. (Engenharia da Produção) - Universidade Federal do Rio Grande de Norte, Natal.

Fernandes, A.G, Furtado, R. P. M., \& Ferreira, P. A. (2016). Aplicação do Balanced Scorecard no auxílio à formulação do planejamento estratégico no setor público: o caso DAE/UFLA. E\&G Economia e Gestão, 16 (42), pp. 218-244.

Gomes, A. P. S. (2006). O papel do Balanced Scorecard na avaliação de desempenho do sistema policial português. Tese. (Contabilidade e Auditoria) - Universidade do Minho Escola de Economia e Gestão, Braga.

Kaplan, R.S., \& Norton, D. P. (1997). A estratégia em ação: balanced scorecard. (22a. ed.). Rio de Janeiro: Campus.

Mason, R. O., \& Swanson, E. B. (1981). Measurement for management decision. California: Addison-Wesley.

Matias-pereira, J. (2018). Administração pública: foco nas instituições e ações governamentais. (5a ed.). São Paulo: Atlas.

Neely, A. (1998). Measuring business performace. London: The Economist In Association With Profile Books.

Rezende, D. A. (2015). Planejamento estratégico público ou privado: guia para projetos em organizações de governo ou de negócios. (3a. ed.). São Paulo: Atlas.

Taffarel, M. (2018). O Balanced Scorecard como ferramenta estratégica para pequenos municípios. Revista Brasileira de Políticas Públicas e Internacionais, 3(2), pp. 59-80.

Teixeira, A. A; Cruz, J.A; \& Fosenca, P.G. (2015). Administração Pública dos serviços de saneamento básico: uma análise da aplicabilidade da gestão estratégica com o uso do Balanced Scorecard - BSC na empresa baiana de águas e saneamento - EMBASA. Revista Multidisciplinar e de Psicologia, 9 (25), pp. 159-179. 